extends from the fixation point outward $25^{\circ}$. Vision $=$ fingers at 4 feet.

The fundus of the left eye is normal. Vision $=6 / 6$.

\title{
ANNOTATION
}

\section{The Ciliary Muscle}

It is usually held that the discovery of the ciliary muscle was made simultaneously by Sir William Bowman and Professor Bruecke. Their discovery was independent of each other; and Bowman announced his views at a meeting of the British Association, held at Oxford in 1847.

In this connection it is curious that the priority of the discovery of the true nature of the ciliary muscle by Knox, the celebrated extramural teacher of anatomy at Edinburgh, has been entirely overlooked.

Knox read a paper on "The Comparative Anatomy of the Eye," before the Royal Society at Edinburgh, on June 17, 1823.

In this paper Knox tried to demonstrate that the adaptation of the eye to varying distances is effected by the ciliary muscle, "or that body which anatomists have hitherto called the ciliary ligament." In the "Life of Knox," by Lonsdale, from which we quote, it is stated that: "Though furnished only with a simple lens, he maintained that the Annulus albus showed no ligamentous fibres. but comparatively large branches of nerves; that it did not resemble any of the textures of the eyeball except the iris, but that here the resemblance was so close that they could with difficulty be distinguished." "Having discovered that in birds, and in the deer, the so-named (ciliary) ligament received numerous nerves, that its texture bore no resemblance whatever to ligament, that it became rudimentary in those animals whose sight was feeble, which would not necessarily happen were it simply a ligament for the suspension of the tunics and humours of the eye, the conclusion was irresistible that the Annulus albus is a muscle, that it is the muscle by which the eye adapts itself to the perception of distant objects; and that by it, in conjunction with the iris, all the changes which take place in the interior of the eyeball are effected."

Knox remarked that "the development of the ciliary muscle followed the ratio of the strength of vision, or rather of the accommodating powers of the eye in the various classes of animals; id est, it is strong in birds, in man, in the quadrumana, and in the deer; weaker in some others of the ruminantia, as the ox; still more so in the horse. Lastly, in most fishes it is completely rudimentary, and is reduced to a mere ligament." 
"At a meeting of the Anatomical and Physiological Society of Edinburgh, in 1836, Knox referred to the Archives Génerales of that year, containing an analysis of various German monographs on the structure and physiology of the eyeball, and the confirmation of his views on the Annulus albus by Arnold."

As is well known, Knox was the anatomist who received most of the bodies of the victims of Burke and Hare; after 1830, his career as a great teacher was practically over; and perhaps the odium attaching to his name on account of his association with the West Port murders may have led men to overlook his research work and its results.

\section{INTERNATIONAL OPHTHALMOLOGICAL CONGRESS, HOLLAND, September 5-13, 1929.}

\section{Subscribers to International Ophthalmological Council Fund}

\section{FIFTH LIST}

Societies, Institutions, etc.

Bulgarian Ophthalmological Society. Society of Oculists of West Poland.

INDIVIDUALS.

$\begin{array}{ll}\text { Marquez, M. } & \text { Vail, Derrick T., Jr. } \\ \text { Preziosi, L. } & \text { Weed, Harry M. }\end{array}$

We desire to remind any ophthalmologists who intend to go to Amsterdam for the Congress and who have not yet sent their subscriptions that it will greatly facilitate the work of the National Committee if they will do so at once. Seven hundred members have already been enrolled and 232 communications covering all branches of Ophthalmology have been promised. Even if any reader is unable to attend the meetings he will find it almost essential to possess himself of a copy of the Transactions, which promise to form a compendium of recent work in Ophthalmology. So that even those who do not see their way to go to Holland should, at least, become members so that they may be supplied with a copy of the Transactions when they appear.

Subscriptions (25 Dutch florins $=£ 22 \mathrm{~s}$. English money) should be sent to

Dr. H. M. Roelofsz,

Director of the Incassobank,

Heerengracht 531,

Amsterdam. 